\title{
REMOTE SENSING ANALYSIS OF VOLUME IN TAIHU LAKE: APPLICATION FOR ICESAT/HYDROWEB AND LANDSAT DATA
}

\author{
Y. Liu ${ }^{1}, \mathrm{Y} . \mathrm{Li}^{1}, \mathrm{Y} . \mathrm{Lu}^{1}, \mathrm{H} . \mathrm{Yue}^{1 *}$ \\ ${ }^{1}$ College of Geomatics, Xi' an University of Science and Technology, Xi'an, Shaanxi 710054, China - liuying712100@163.com, \\ 865736425@qq.com,823554110@qq.com,yue_hui@live.com
}

Commission III, WG III/9

KEY WORDS: Taihu Lake, Surface area, Water level, Lake Volume variation, Water balance

\begin{abstract}
:
In order to evaluate the fluctuation of Taihui Lake, ICESat/Hydroweb and Landsat data recorded from 1975 to 2015 were used to examine changes in lake level and area, derived from Normalized Difference Water Index (NDWI) and Modified Normalized Difference Water Index (MNDWI), which are combined to indirectly evaluate water volume variations and water balance of Taihu Lake. The results show that the time series of lake area and volume variations of Taihu Lake exhibit a gradually increasing trend from 1975 to 2015 and the value rose from $2320.07 \mathrm{~km}^{2}$ and $-0.0470 \mathrm{~km}^{3}$, respectively in 1975 to $2341.06 \mathrm{~km}^{2}$ and $0.2759 \mathrm{~km}^{3}$, respectively in 2015. The water level of Taihu Lake demonstrates a fluctuating trend during 1975-2015 and the value changed from $0.9826 \mathrm{~m}$ in 1975 to $1.1359 \mathrm{~m}$ in 2015 . There was a moderate correlation for Taihu Lake $\left(\mathrm{R}^{2} \approx 0.65\right)$ between water level and surface area. The water volume changes was in very good agreement for lake level changes and surface area variations $\left(\mathrm{R}^{2}>0.85\right)$. Combining with lake level and area changes, water balance of Taihu Lake was acquired and it shows a positive water budgets of $0.0092 \mathrm{~km}^{3}$ during past 40 years.
\end{abstract}

\section{INTRODUCTION}

In recent years, due to the impacts of climate change and human activities, many lakes in China has been shrinking, both on the water level and the volume. The phenomenon of subtraction has a profound impact on local economic development, climate and ecological changes, so it is very important to monitor the dynamic changes of lakes (Feyisa et al., 2014; Li et al., 2013). Domestic and foreign scholars have done a lot of research on the area, water level and volume of our lakes by using remote sensing technology (Fabich and Kwidzińska, 2012; Lu et al., 2013; Duan and Bastiaanssen, 2013). Taihu Lake is one of the five largest freshwater lakes in China, and the research on its development using remote sensing technology mainly focuses on the eutrophication and water quality monitoring (Zhang et al., 2014; Zhang et al., 2015). Although scholars at home and abroad have done some research on the area of Taihu Lake and the change of water level. Based on Taihu lake as the research object, using Landsat data from 1975-2015 ICESat from 2003-2009 and Hydroweb data from 2000 to 2010 to get its area and water level data, on this basis, the study of its volume change and influence factors, in order to get to the Taihu lake water dynamic change rule and driving factors, to protect the Taihu lake and the government provide basis and reference for the corresponding protection policy and water temperature, the time series and water balance of Taihu volume change have been reported less.

Taihu Lake is the third largest freshwater lake in China and is located on the southern bank of the Yangtze River Delta, between $30^{\circ} 55^{\prime} 40^{\prime \prime} \mathrm{N}$ to $31^{\circ} 32^{\prime} 58^{\prime \prime} \mathrm{N}$ and $119^{\circ} 52^{\prime} 32^{\prime \prime} \mathrm{E}$ to $120^{\circ} 36^{\prime} 10^{\prime \prime} \mathrm{E}$. (Figure 1). Taihu Lake plays an important role in providing water resources, river basin flood control, water regulation, and maintaining local people's lives. In recent years, with the development of social economy and the influence of natural and human factors, the constantly changing area of Taihu Lake and the eutrophication of water bodies have been aggravated, seriously affecting the development of the local ecology, society and economy (Zhang et al., 2013).

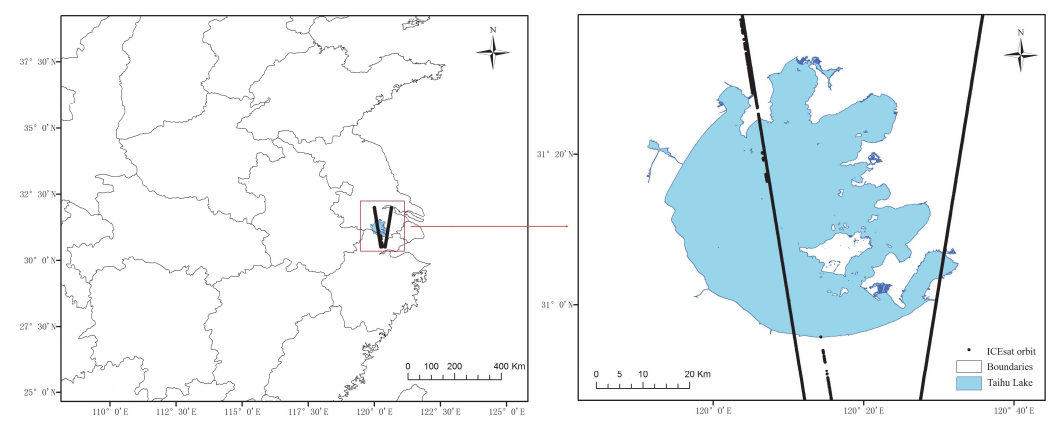

Figure 1. The location of Taihu Lake

* Corresponding author 


\section{DATA AND METHODS}

\subsection{Landsat data and area extraction}

Using 106 images from 1975-2015 Landsat MSS/TM/ETM+/OLI data to extract Taihu Lake area, those data was downloaded from the U.S. geological survey (http://glovis.usgs.gov/).After the data strip repair, stitching, radiation correction, atmospheric correction and other pretreatment surface reflectivity. For the Landsat MSS data, the lake boundary was extracted using the Normalized Difference Waters Index (NDWI) due to the absence of mid-infrared band. Lakes boundary was extracted using Landsat TM/ETM+/OLI data using the Modified Normalized Difference Water Index (MNDWI). The maximum variance between classes, proposed by Otsu in 1979, which was used to determine the threshold of water and non-water in each image.

\subsection{ICESat/Hydroweb data}

The GLA14 data for the ICESat / GLAS Global Terrestrial Data Product, as used herein, was downloaded from the National Snow and Ice Data Center (http://id.idc.org/data/icesat/) and received from the 2003-02-23 to $2009-10-11$, the latest data version is 34 . Obtain time series data for study water level using the NSIDC GLAS Altimetry elevation extractor Tool (NGAT) tool. Taihu Lake water level data from 2000 to 2010 are from Hydroweb (http://www.LEGOS.obs-mip.fr/soa/hydrologie/HYDROWEB). The reference ellipsoid of ICEsat data is TOPEX/Poseidon (T/P), geoid is EGM2008 Geoid, and the reference ellipsoid of Hydroweb data is GRACE Gravity Model 02 (GGM02), in order to facilitate the integration of data, convert the reference ellipsoids of both data to the WGS84 ellipsoid. The water level information for 1975-1999 and 2011-2015 was derived based on the statistical relationship between area and water level.

\subsection{Volume changes}

The method of Taube [26] is used to calculate the volume change of Taihu Lake. The formula is:

$$
\Delta V=\frac{1}{3}\left(H_{1}-H_{0}\right) \times\left(A_{0}+A_{1}+\sqrt{A_{0} \times A_{1}}\right)
$$

In the formula: $\Delta \mathrm{V}$ represents the amount of change in the lake volume, $\mathrm{H}_{0}$ and $\mathrm{A}_{0}$ represent the initial water level and area over the study period (in this paper, the 1975 water level and area data), and $\mathrm{H}_{1}$ and $\mathrm{A}_{1}$ represent the next stage water level and area data.

Using Equation 2 to calculate Taihu Lake water balance data, specifically:

$$
\Delta V_{1}=\frac{1}{3}\left(H_{2}-H_{1}\right) \times\left(A_{2}+A_{1}+\sqrt{A_{2} \times A_{1}}\right)
$$

In the formula: $\Delta \mathrm{V}_{1}$ is the change of volume of two adjacent lakes, $\mathrm{H}_{1}$ and $\mathrm{H}_{2}$ are the water levels of two adjacent periods, $\mathrm{A}_{1}$ and $\mathrm{A}_{2}$ are the adjacent two periods. The lake volume balance data can be obtained by adding the incremental volume changes of the lake volume gradually.

\section{RESULTS AND ANALYSIS}

\subsection{Taihu Lake area change analysis}

Calculate the area of Taihu Lake in each period of each year to obtain the trend of Taihu Lake area change from 1975 to 2015. The overall Taihu Lake area shows a slow growth trend $\left(\mathrm{R}^{2}=0.351\right)$ over the past 40 years. The area increased from $2320.07 \mathrm{~km}^{2}$ in 1975 to $2341.06 \mathrm{~km}^{2}$ in 2015 , with an increase of $15.17 \mathrm{~km}^{2}$, showing no obvious growth trend. Figure 3 shows the shoreline changes in Taihu Lake. Changes in the shoreline of the Taihu Lake mainly occurred in the northeast and southeast (Figure 3). In 1990 and 1999, the shoreline significantly expanded and the shoreline contracted in 1997. Further analysis shows that there are obvious seasonal changes in the lake shoreline. The area of the lake during the rainy season is large, and the area of the lake at other times is small.

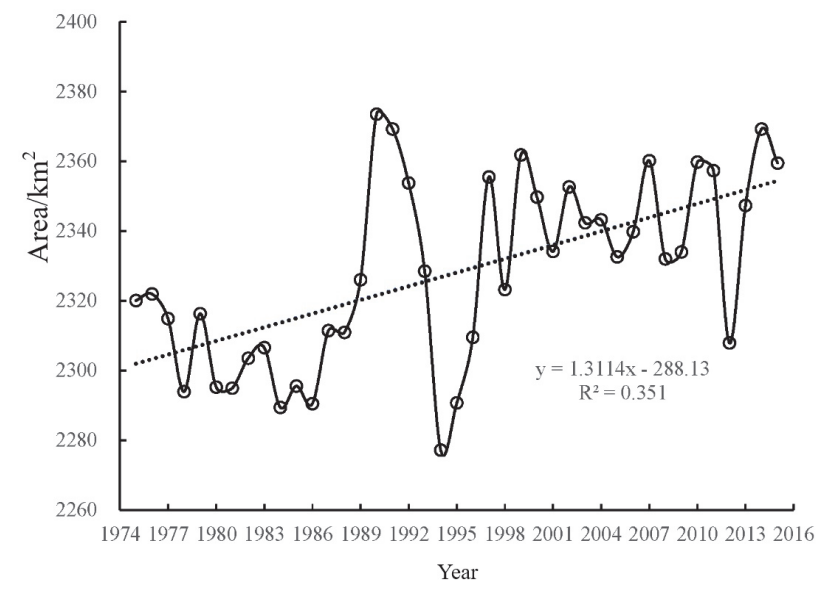

Figure 2. The estimated surface area time-series during 19752015 from Landsat of Taihu Lake
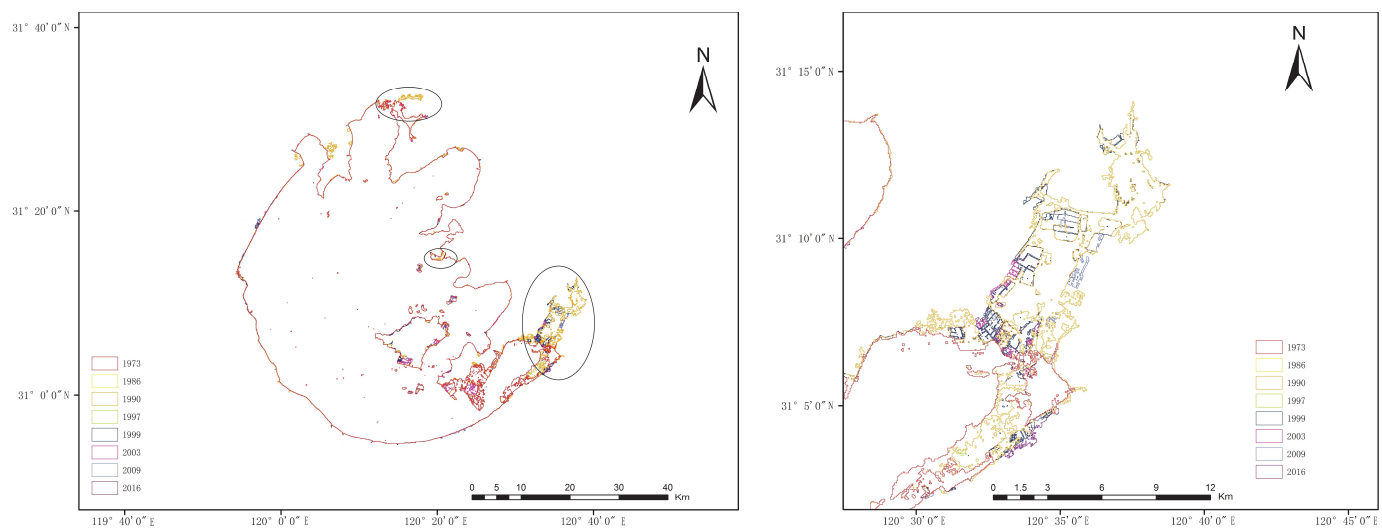

Figure 3. Lake boundaries extracted from Landsat imagery and the enlarged views of shoreline changes 


\subsection{Taihu Lake water level changes analysis}

Since the ICESat and Hydroweb data only provide information on the Taihu Lake water level data from 2000 to 2010, the water level data before and after the year 2000 cannot be obtained directly. In the research process of this paper, the water level-area function is constructed by using the same or similar area data with the same water level and time phase. Taihu Lake water level and the functional relationship between the area as follows: $\mathrm{Y}=0.00389 \mathrm{X}-8.0425\left(\mathrm{R}^{2}=0.65, \mathrm{P}<0.01\right)$, the functional relationship between the water level and the area of Taihu Lake established by the article is limited by the data error of ICESat water level and the short time series.

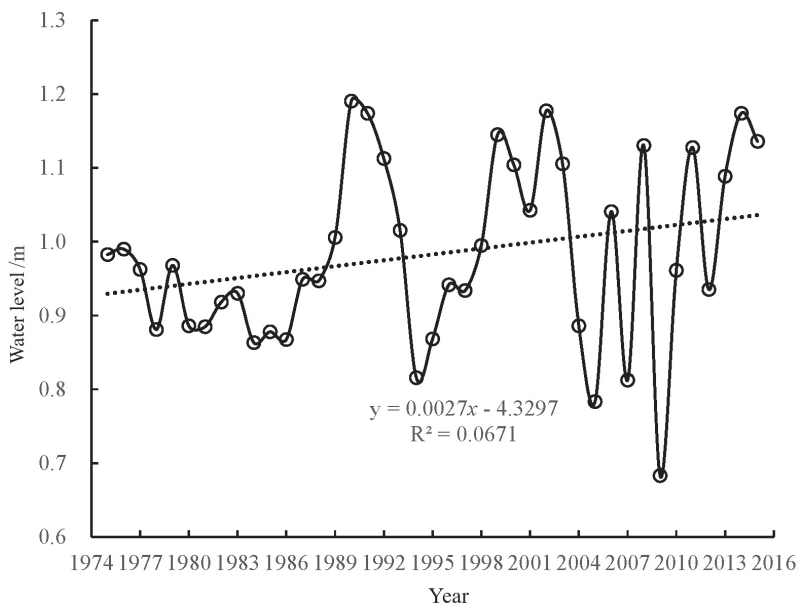

Figure 4. Water level time-series during 1975-2015 of Taihu Lake

\subsection{Taihu Lake volume change analysis}

Combining the area of Taihu Lake and the water level, the water balance of Taihu Lake is $0.0092 \mathrm{~km}^{3}$, which is calculated by using Equation 2. The change is small and the amount of water basically remains unchanged.

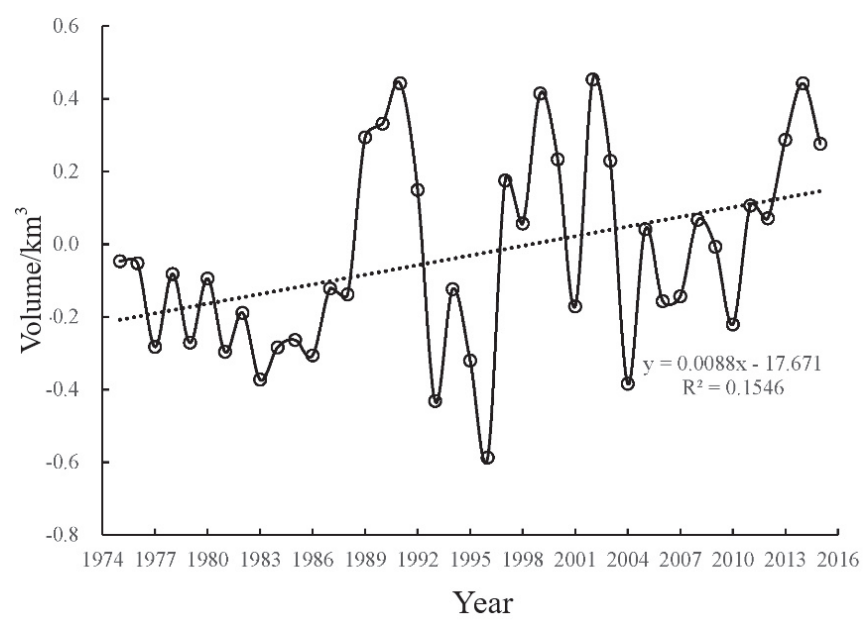

Figure 5. Volume changes time-series during 1975-2015 of Taihu Lake

\section{RESULTS AND DISCUSSION}

ICESat, Hydroweb, and Landsat data are increasingly used in the study of long-term dynamic processes of water bodies. In this paper, the ICESat, Hydroweb, and Landsat data from 1975 to 2015 were used to extract Tai Lake area and water level data. Based on the data, the volume change data was obtained and the influencing factors of Taihu Lake water dynamic change were studied. The main conclusions were: Over the past 40 years, the area, water level, and volume of Taihu Lake have generally risen slightly, rising from $2320.07 \mathrm{~km}^{2}, 0.9826 \mathrm{~m}$, $0.0470 \mathrm{~km}^{3}$ in 1975 to $2341.06 \mathrm{~km}^{2}$ in $2015.1359 \mathrm{~m}, 0.2759$ $\mathrm{km}^{3}$; Taihu Lake water balance did not change much, it was 0 . $0092 \mathrm{~km}^{3}$. The increase in the amount of water entering the lake, the change in annual rainfall and annual evaporation, and the government's policy of "returning land to lake" are the main reasons for the dynamic changes in Taihu Lake.

\section{ACKNOWLEDGEMENTS}

This work is partially supported by grants from The National Natural Science Foundation of China (Grant No. 41401496) and China Postdoctoral Science Foundation Funded Project (Grant No. 2016M592815).

\section{REFERENCES}

Duan, Z., \& Bastiaanssen, W. G. M., 2013. Estimating water volume variations in lakes and reservoirs from four operational satellite altimetry databases and satellite imagery data. Remote Sensing of Environment, 134(5), pp.403-416.

Fabich, A., \& Kwidzińska, M., 2012. Changes in the water surface area of lakes udzierz and mątasek in the light of cartographic materials. Limnological Review, 12(4), pp.169-177.

Feyisa, G. L., Meilby, H., Fensholt, R., \& Proud, S. R., 2014. Automated water extraction index: a new technique for surface water mapping using landsat imagery. Remote Sensing of Environment, 140(1), pp.23-35.

Li, W., Du, Z., Ling, F., Zhou, D., Wang, H., \& Gui, Y., et al., 2013. A comparison of land surface water mapping using the normalized difference water index from tm, etm + and ali. Remote Sensing, 5(11), pp.5530-5549.

Lu, S., Ouyang, N., Wu, B., Wei, Y., \& Tesemma, Z., 2013. Lake water volume calculation with time series remote-sensing images. International Journal for Remote Sensing, 34(22), pp.7962-7973.

Zhang, F., Li, J., Shen, Q., Zhang, B., Wu, C., \& Wu, Y., et al., 2015. Algorithms and schemes for chlorophyll a estimation by remote sensing and optical classification for turbid Lake Taihu, china. IEEE Journal of Selected Topics in Applied Earth Observations \& Remote Sensing, 8(1), pp.350-364.

Zhang, F., Zhang, B., Li, J., Shen, Q., Wu, Y., \& Wang, G., et al., 2014. Validation of a synthetic chlorophyll index for remote estimates of chlorophyll-a in a turbid hypereutrophic lake. International Journal of Remote Sensing, 35(1), pp.289-305.

Zhang, G. Q., Xie, H. J., Yao, T. D., \& Kang, S. C., 2013. Water balance estimates of ten greatest lakes in china using Icesat and Landsat data. Chinese Science Bulletin, 58(31), pp.3815-3829. 